\title{
Filosofia e investigação para a paz
}

Philosophy and Peace Research

Philosophie et recherche pour la paix

\section{Vicent Martínez Guzmán}

Tradutor. Tatiana Moura

\section{(2) OpenEdition}

\section{Journals}

\section{Edição electrónica}

URL: http://journals.openedition.org/rccs/1015

DOI: $10.4000 /$ rccs. 1015

ISSN: 2182-7435

\section{Editora}

Centro de Estudos Sociais da Universidade de Coimbra

Edição impressa

Data de publição: 1 junho 2005

Paginação: 43-62

ISSN: 0254-1106

\section{Refêrencia eletrónica}




\section{VICENT MARTÍNEZ GUZMÁN}

\section{Filosofia e investigação para a paz}

Como seres humanos, temos competências para organizar as nossas relações, fazendo uso da guerra e de qualquer outro tipo de violência estrutural, cultural ou simbólica, que suponha a marginalização, exclusão e morte de uns seres humanos por outros e a degradação do ambiente. Mas também é certo que temos competências para organizar as nossas relações de forma pacífica: exprimindo ternura ou carinho nas relações interpessoais ou criando instituições de governação locais, estatais ou globais que promovam relações humanas baseadas na justiça e relações com a natureza baseadas na sustentabilidade. Neste contexto, o desafio filosófico dos estudos para a paz é a reconstrução normativa das nossas competências para fazer as pazes.

\section{Introdução}

Neste trabalho, ${ }^{1}$ apresentarei uma exposição sumária da aproximação à Investigação para a Paz realizada na Cátedra UNESCO de Filosofia para a Paz. Como o próprio nome indica, a minha perspectiva parte dos instrumentos de reflexão filosófica em que me formei. Abordar a Investigação para a Paz sob esta vertente supõe, desde logo, o reconhecimento de uma forma de entender a própria investigação. Pensamos que as investigações e os estudos para a paz requerem aproximações multidisciplinares e multiculturais. Deste modo, dadas as próprias características dos objectivos destas investigações e a sua relativa novidade, serão também interdisciplinares e interculturais.

Creio que o que está em jogo é a tomada de consciência do sofrimento que os seres humanos podem gerar uns aos outros e à própria natureza, e a busca de formas pacíficas de transformação das relações humanas que sejam alternativas às guerras, à marginalização e à exclusão que são expressões desse sofrimento. Para estes dois objectivos mínimos da investigação para a paz, tomada de consciência do sofrimento e indagação de formas pacíficas de transformação, não há nem uma disciplina nem uma cultura que tenha a

\footnotetext{
${ }^{1}$ Estas reflexões resultam do projecto de investigação "Desarrollo, Dialogo y Responsabilidad Corporativa”, Projecto I+D+I do Ministerio de Educación y Ciencia español, co-financiado pelos fundos FEDER, ref. HUM2004-06633-C02-02/FISO.
} 
patente da solução. São objectivos tão importantes para a configuração pacífica das relações humanas que temos de estar criticamente atentos a que uma cultura ou campo de estudo se converta em paradigma dominante das soluções porque, pela própria natureza dos problemas a tratar, se uns saberes e culturas se apresentam como dominantes, convertem-se em dominadores e, por conseguinte, convertem outros saberes e culturas em dominados, submetidos e excluídos. Dominação, submissão e exclusão são precisamente algumas das causas do sofrimento a que nos referíamos e, portanto, não podem ser considerados meios pacíficos da sua transformação.

Por estas razões, nas investigações e nos estudos para a paz é necessária uma convergência multidisciplinar, de muitas disciplinas, e multicultural, de muitas, de todas as culturas ou modos através dos quais os grupos humanos demonstraram a sua capacidade em cultivar as próprias relações entre os seus membros e com a natureza. No entanto, para estar alerta contra o perigo de imposição de uns saberes ou de umas culturas e submissão de outros, que infelizmente ocorre com demasiada frequência, necessitamos também da interdisciplinariedade e interculturalidade. Ou seja, a interpelação recíproca entre disciplinas e culturas. Não é suficiente o reconhecimento da multiplicidade ou pluralidade. A investigação e os estudos para a paz têm que estar submetidos à riqueza das tensões, matizes, transformação positiva das contradições entre essas culturas e saberes plurais para reconstruir, a partir do reconhecimento e de forma dinâmica, aquelas características que se vão configurando em cada momento, como indicadores de transformação pacífica das relações humanas que produzam guerras, marginalização, miséria ou exclusão.

Creio que estas reflexões iniciais poderão conferir sentido à amplitude de temas que, desde os seus inícios nos anos 50 até aos dias de hoje, se foram incorporando na investigação e nos estudos para a paz: estudos sobre a guerra, o desarmamento e a violência; o papel dos movimentos sociais e das ONG na ajuda humanitária; a teoria das relações internacionais; as teorias dos conflitos, desde os inter-pessoais à configuração da ordem mundial; as teorias do desenvolvimento e o papel das ONGD; os contributos feministas e a adopção de perspectivas assentes na diferença sexual, incluindo a dimensão ecológica e, por conseguinte, ecofeminista; as teorias do pós-desenvolvimento e as análises pós-coloniais; os contributos dos saberes considerados "indígenas" pelo saber científico dominante do Norte ocidental do mundo, considerados como saberes de menor categoria científica e, assim, convertidos em saberes dominados; as reflexões críticas sobre os direitos humanos, o direito internacional humanitário e, em geral, o direito 
internacional; a reforma das formas de governação locais e globais em novos contextos de culturas para fazer as pazes, mais comprometidas local e globalmente; o desenvolvimento da democracia cosmopolita; a apresentação de alternativas ao globalismo totalitário e unilateral, por uma genuína globalização capaz de fazer frente ao tema da pobreza e da fome e à má distribuição dos recursos mundiais, muitas vezes ocultos pelo impacto mediático do chamado terrorismo global que também deve ser estudado...

Seguramente, quem lê estes temas a partir da sua própria experiência de investigação para a paz encontrará matizes, alternativas, carências ou excessos nas abordagens temáticas: excelente, já que será um sintoma de que a partir de outras experiências, saberes ou culturas, podemos interpelar-nos e praticar a interdisciplinariedade e a interculturalidade. Quantos mais formos para penetrarmos nas brechas do bloco do pensamento único, mais possibilidades teremos de o fragmentar, para apresentar as nossas alternativas com base na diversidade.

A proposta que vou analisar e na qual trabalhamos há mais de dez anos, é a de que, enquanto seres humanos, temos competências ou capacidades para organizar as nossas relações, fazendo uso das guerras e de qualquer outro tipo de violência estrutural, cultural ou simbólica que suponha, como já mencionei, a marginalização, exclusão e até a morte de alguns seres humanos por outros e a depredação do meio ambiente. No entanto, também é certo que temos competências ou capacidades para organizar as nossas relações de forma pacífica, desde a expressão da ternura ou do carinho nas relações interpessoais, até à criação de instituições de governação locais, estatais ou globais que promovam relações humanas baseadas na justiça, bem como relações com a natureza baseadas na sustentabilidade.

Isto significará desde logo que estamos empenhados em trabalhar com propostas realistas. Longe daqueles que, considerando-se a si mesmos realistas, qualificaram os estudos para a paz como um "realismo ingénuo" ou "uma certa utopia", de que fica bem falar, mas na certeza de que a realidade vai por outros caminhos, a nossa posição consiste na denúncia desse "falso realismo" e na defesa da possibilidade de realização das nossas próprias propostas. Denunciamos essa atitude como falso realismo porque não considera as relações humanas em toda a sua complexidade: já admitimos que os seres humanos têm competências ou capacidades para fazer muito mal, até para a aniquilação total. Nisto estamos de acordo com os falsos realistas. No entanto, quedarmo-nos por estas afirmações é distorcer as capacidades dos seres humanos, é um idealismo de má fé, que se converte numa ideologia que sustenta as situações de dominação, exclusão, marginaliza- 
ção e depredação da natureza, com o argumento de que "não há solução para a fome no mundo" ou de que "a única alternativa possível era bombardear o Iraque”.

A nossa proposta é mais realista, porque, ainda que reconheçamos as capacidades e competências para gerar sofrimento, reconhecemos também as capacidades e competências para tornar efectivas todas as outras coisas que já dissemos que também podemos fazer entre nós: tratar-nos com ternura e carinho na esfera interpessoal e criar instituições de governação com justiça nos diferentes contextos institucionais. É verdade que também temos este segundo tipo de capacidades e competências e podemos sempre pedir-nos contas do tipo de capacidades que exercemos nas nossas relações, entre nós e com a natureza.

Daqui resulta que a nossa proposta de definição de filosofia para fazer as pazes seja a reconstrução normativa das nossas capacidades ou competências para viver em paz. Para desenvolver esta definição, em primeiro lugar, referir-me-ei à concepção dos seres humanos que está presente na nossa abordagem; isto é, à possível antropologia filosófica que nos sirva de referência para dialogar com as investigações e com os estudos para a paz. Em segundo lugar, sintetizarei os argumentos com base nos quais temos sugerido que a nossa aproximação filosófica aos estudos para a paz requer uma mudança na maneira como dizemos que "sabemos" o que podemos fazer e que sabemos que podemos fazer as pazes; ou seja, referir-me-ei à proposta filosófica da necessidade de uma mudança epistemológica nas investigações e estudos para a paz. Finalmente, situarei essa possível antropologia filosófica e essa nova maneira de entender o estatuto epistemológico das investigações e estudos para a paz numa nova forma de entender a política, ligada às culturas para fazer as pazes e que resumirei com a expressão "localismo cosmopolita".

\section{Uma concepção dos seres humanos a partir da filosofia para fazer as pazes} $\mathrm{Na}$ tradição filosófica ocidental, referir-se a uma concepção dos seres humanos é fazer antropologia filosófica. No entanto, a cautela auto-crítica que nos impusemos, para evitar que o nosso próprio discurso seja um exercício de dominação por parte de alguns seres humanos sobre outros, ou de uma cultura ou um saber impostos a outros, faz-nos reflectir sobre o próprio termo "antropologia".

A denominação "antropologia" vem de ánthropos, em grego. Ainda que se discuta sobre a sua etimologia, alguns autores (Landmann, 1961: 18) afirmam que a primeira metade da palavra está relacionada com ánor: homem no sentido masculino. De facto, remonta à raiz indo-europeia ner- que signi- 
fica força vital e homem (Roberts e Pastor, 1997). A segunda parte seria $o p s$, que tem o sentido de olho, mas também cara, aspecto, rosto. Por conseguinte, ánthropos significa algo com aspecto ou rosto de homem. É certo que muitas vezes se lhe atribuiu o significado genérico de ser humano, por oposição, por exemplo, aos deuses. No entanto, haveria implicitamente uma exclusão, uma subvalorização e até dominação das mulheres pelos homens $\mathrm{e}$, nesse sentido, teriam razão algumas teorias feministas quando acusam os discursos antropológicos em geral de androcêntricos: de estarem centrados unicamente nos seres humanos masculinos.

Por outro lado, o latim homo leva-nos a outra interessante etimologia que destaca a nossa pertença à terra, como se comprova com a sua raiz comum com bumus, solo e terra que, em grego, Landmann relaciona com brotós entendido como mortal e terreno. A raiz indo-europeIa de "humano" é $d$ hghem - que significa literalmente "terra". Por sua vez, este significado coincidiria com o hebreu Adam, usado no mito da criação do Génesis, que viria de adama, terra. Voltaremos à afirmação da natureza terrena dos seres humanos.

Outro elemento a ter em conta numa concepção dos seres humanos criticamente atenta à dominação e exclusão de uns e umas por outros e outras é o etnocentrismo: só somos verdadeiramente humanos os do nosso povo, raça ou nação. Vai-se deste modo construindo a noção de estranho, estrangeiro, bárbaro (o que gagueja, balbuceia ou não fala como nós) e, em última análise, de inimigo. Landmann interpreta que, inclusivamente, o mandamento bíblico de amar o próximo como a si mesmo $(\operatorname{Lev} 19,18)$ pressupõe como natural o amor a si mesmo e o que faz é acrescentar o amor ao próximo. Assim, também do ponto de vista colectivo o amor dá-se primeiro com os "nossos" e depois com os outros, como nos recorda o mesmo Levítico (19, 33-34), não obstante o que a citação seguinte contém de acolhimento dos estrangeiros ou forasteiros : "Se um estrangeiro vier residir contigo na tua terra, não o oprimirás. $\mathrm{O}$ estrangeiro que reside convosco será tratado como um dos vossos compatriotas e amá-lo-ás como a ti mesmo porque fostes estrangeiros na terra do Egipto”. Este tipo de etnocentrismo faz-se acompanhar da consideração do nosso próprio povo como o "povo eleito".

Atentos, portanto, às relações de dominação (das outras, dos outros povos e culturas e da terra), a nossa concepção de ser humano parte do reconhecimento de que vivemos necessariamente em interacção e interdependência. Segundo Hannah Arendt (1996), a vita activa dos seres humanos na terra está condicionada pela sustentabilidade biológica da vida (labor), a criação de artifícios através do trabalho, e a dimensão que mais nos interessa neste contexto: as relações entre os seres humanos a que chama acção. A condi- 
ção humana da acção, o que caracteriza e condiciona os seres humanos nas suas relações entre eles mesmos na sua vida na terra, é a "pluralidade": somos todos seres humanos e não $o$ Ser Humano, os que vivemos na terra e habitamos o mundo. Há que dizer que nas minhas próprias reflexões utilizo uma linguagem que, influenciada pelo alerta crítico das teorias feministas, está mais atenta à discriminação por motivos de sexo que a de Arendt, ela própria mulher. De facto, ela fala "do Homem" e "dos homens" (1996: 22).

Na minha interpretação, como seres humanos temos que estar conscientes da nossa natureza terrena, que já vimos no mito de Adão e na própria etimologia de "humano" que vem de humus, terra. Em primeiro lugar, esta natureza terrena confere uma dimensão ecológica à nossa concepção do ser humano a partir da nossa filosofia para fazer as pazes: somos parte da terra que, para viver em paz, temos que cultivar e cuidar como alternativa à depredação como forma de violência contra a natureza.

Em segundo lugar, esta natureza terrena torna-nos também humildes em relação ao que imaginamos que sejam os deuses. "Humildade" também está relacionado com "humus", como o adjectivo humano. O adjectivo bumilis significa "de pouca altura", no sentido de mais ligado à terra. No entanto, de certa forma, também quisemos dominar os deuses. A arrogância de pretender ser como eles chamava-se, na mitologia grega, bybris. A resposta era a justiça como vingança, Némesis, em lugar da justiça, Díke, irmã do bom governo (Eunomia) e da paz (Eirene) (Martínez Guzmán, 2001). É a mesma arrogância que aparece no mito da criação do Génesis no qual a tentação dos seres humanos consiste em querer "ser como Deus". Uma recente experiência dessa falta de assunção da nossa humildade como natureza terrena foi o terrorismo internacional que, em nome de Alá, fez explodir aviões contra as torres gémeas, e a resposta de "justiça infinita", justiça como vingança, nos bombardeamentos do Afeganistão e na invasão do Iraque (Martínez Guzmán, 2004a; 2004b). Em ambos os casos, não há uma aceitação da humildade-natureza terrena, como condição humana: ambas as partes julgaram ser como deuses ou actuar em nome de Deus.

Em terceiro lugar, e segundo Arendt, afirmamos que as relações entre os seres humanos se caracterizam pela pluralidade. Esta pluralidade tem um duplo carácter de "igualdade" e de "distinção". Temos que ser suficientemente iguais para poder entender-nos e suficientemente diferentes para ter algo que dizer. A acção consiste em tomar a iniciativa, começar, conduzir, governar, pôr algo em movimento. Os seres humanos, como agentes das nossas acções, revelamo-nos na acção e no discurso porque vivemos uns e umas com outros e outras, em "pura contiguidade humana" (Arendt, 1996: 
206). Para além de nos revelarmos uns aos outros como agentes, arcamos também com as consequências das nossas acções. "Fazer e sofrer são como as duas faces da mesma moeda" (1996: 213). É precisamente a ruptura da contiguidade em que vivemos que converte os outros e as outras em inimigos e marca o início da violência.

Aquela humildade que reivindicávamos como expressão da nossa natureza terrena apresenta-se agora como "fragilidade" por falta de antecipação do resultado do que fazemos aos outros/as. Somos tão frágeis que muitas vezes não sabemos onde nos poderá levar o que podemos fazer uns aos outros/as. Por isso, na terminologia grega, agrupámo-nos e fundámos a polis. "A esfera política surge ao actuarmos juntos, ao "partilhar palavras e actos" (Arendt, 1996: 221).

Por conseguinte, a nossa concepção do ser humano implica uma concepção da política como o instrumento que, como seres humanos, temos para fazer frente à fragilidade humana, que aparece quando nos damos conta da imprevisibilidade das nossas acções (Martínez Guzmán, 2003). Por isso, o "poder corresponde à capacidade humana, não simplesmente para actuar, mas para actuar concertadamente" (Arendt, 1998: 146). A violência consiste no uso de ferramentas que não distingue entre meios e fins. $\mathrm{Na}$ atitude violenta, em vez de fazermos políticas para a nossa fragilidade, superamos os fins que queremos conseguir com os meios que utilizamos para alcançá-los, e as acções, fruto da nossa fragilidade, "escapam das nossas mãos", os meios sobrepõem-se aos fins. O meio "invasão do Iraque" foi muito para além do fim de eliminar a ditadura de Hussein e de encontrar as armas de destruição em massa que, no final, não existiam. A violência rompe a capacidade de concertação que podemos usar nas nossas políticas para a fragilidade e introduz a arbitrariedade na imprevisibilidade das nossas acções. Recorre-se então à guerra como solução final, como se ela pudesse solucionar tudo (ibid.: 112s.). A violência, neste sentido, parte das características arrogantes e dominadoras dos seres humanos. Ao invés, a capacidade de concertação, o poder comunicativo, é precisamente o poder da nãoviolência² (Arendt, 1996: 223).

Deste modo, a nossa concepção dos seres humanos para fazer as pazes potencia as suas características de natureza terrena, humildade e fragilidade, para fazer frente à violência, que também faz parte das relações humanas; não de maneira ingénua, mas sim com um forte compromisso político em vista da subordinação dos meios aos fins que se querem alcançar; com

\footnotetext{
2 Escrito como uma só palavra com o objectivo de "positivar" o seu significado imitando o termo hindu abimsa usado por Gandhi e traduzido para inglês também como uma só palavra, nonviolence (Arias, 1995).
} 
políticas que façam frente à fragilidade humana que, certamente, nos torna propensos à violência, à justiça como vingança e à guerra como solução final das consequências das nossas acções, mas também à capacidade de concertação e à justiça que implicam maneiras de fazer as pazes e boas formas de governação.

Este poder comunicativo (Habermas, 1984; 1998) como característica peculiar dos seres humanos que se expressa na capacidade de concertação como forma nãoviolenta de exercer política, exprimo-o também com base nos meus estudos da teoria dos actos de fala. Desta teoria aprendemos que dizer é fazer coisas e compreender-nos é captar a força com que "performamos" ou fazemos, o que nos fazemos, dizemos e calamos (Austin, 1971; Martínez Guzmán, 1999). Em qualquer caso, sempre podemos pedir-nos contas pelo que nos fazemos, dizemos e calamos. Com base nesta teoria dos actos de fala, podemos afirmar que o que nos caracteriza enquanto seres humanos é precisamente essa performatividade ou capacidade de nos fazermos, dizermos e calarmos e pedir-nos contas por isso (Apel, 1986).

Aplicada à filosofia para fazer as pazes, esta característica humana da performatividade significaria que os seres humanos têm capacidades ou competências para se excluírem, marginalizarem e matarem, mas também para viver a nossa plural diversidade e igualdade, e criar instituições de concertação, governabilidade e justiça. Esta é a tese principal em que temos trabalhado, como já referi na introdução (Martínez Guzmán, 2005). Somos competentes para tudo o que impliquem as culturas das guerras e somos competentes para tudo o que impliquem as culturas para fazer as pazes.

A noção de competências para exercer qualquer tipo de violência ou para fazer as pazes é uma ampliação da mesma noção usada por Chomsky (competência linguística) e por Habermas (competência comunicativa). Assim, da mesma forma que a linguística geral seria a reconstrução normativa das competências linguísticas do falante, e a pragmática comunicativa a reconstrução normativa das competências para comunicar de forma bem sucedida, a filosofia para fazer as pazes, inclusivamente a nossa perspectiva filosófica da investigação para a paz, seria a reconstrução normativa das nossas competências para fazer as pazes. Certamente poderão existir reconstruções das nossas competências para exercer a violência. Neste caso, nos nossos trabalhos, seriam antes clarificações que permitam reconstruí-las e desaprendê-las. Evidentemente, o nosso compromisso com a paz compromete-nos com a reconstrução das competências ou capacidades para fazer as pazes. Infelizmente, pode haver também quem reconstrua as competências para exercer os diferentes tipos de violência, para promover ainda mais as próprias violências. 
Dizemos que é reconstrução "normativa" porque, do mesmo modo que na linguística ou na pragmática reconstruímos os indicadores ou critérios normativos de como usar a sintaxe ou comunicarmos, na filosofia para fazer as pazes, investigamos os indicadores ou critérios normativos para viver em paz. Da mesma maneira que, de acordo com esses critérios normativos, sempre podemos pedir-nos contas para comunicarmos melhor, também podemos pedir-nos contas para, inclusive, criar instituições de justiça ou de governação, para exigirmos exercer (performar) as competências para fazer as pazes, em confronto com o exercício das competências para promover a violência. Para além disso, dizemos que é reconstrução e não a simples construção porque não construímos a partir do nada, e sim a partir das capacidades para fazer as pazes que fazem parte da nossa condição humana.

Caracterizar os seres humanos como competentes para performar as suas relações com vista a fazer as pazes está relacionado com a assunção da humildade, fragilidade e natureza terrena que também nos caracterizam. É uma demonstração da necessidade que os seres humanos têm uns dos outros. A descoberta da interdependência, da alteridade e da diferença, especialmente da dependência que os homens têm das mulheres, pode gerar medo (Reardon, 1985). Uma maneira de fazer frente ao medo da alteridade e da diferença é "pôr-se na defensiva", por exemplo, iniciando guerras preventivas, e montar um sistema de segurança agressor no qual se tenta dominar quem é diferente, as mulheres, os outros povos, as outras culturas - o choque de civilizações. Daqui resulta que, na nossa filosofia para fazer as pazes, para além de assumir a necessidade de realizar políticas que afrontem a nossa fragilidade, humildade e natureza terrena, necessitemos também de políticas para enfrentar os nossos medos. É certo que temos experiências que indicam que o medo pode levar-nos a condutas violentas: entro num quarto escuro com um pau na mão "pelo sim pelo não". Não obstante, também é certo que temos experiências pessoais que mostram que o medo pode potenciar a nossa capacidade de ternura e de dependência dos outros e das outras de um ponto de vista pessoal, bem como as possibilidades de criar instituições de justiça e governação que transformem o medo em relações institucionais (Barber, 2004; Villa Martínez, 2002).

Em síntese, a nossa concepção dos seres humanos para fazer as pazes reconhece que a constituição da própria identidade pessoal e colectiva faz-se sempre a partir da interacção com outras identidades e grupos humanos. Não somos, cada ser humano ou cada povo, uma entidade absoluta e fechada em nós mesmos. O medo que pode produzir essa interdependência para constituir a nossa própria identidade pode levar-nos a condutas violentas que fazem parte da condição humana. No entanto, pode também 
levar-nos a organizarmo-nos pessoal e politicamente a partir da assunção da nossa humildade, natureza terrena e fragilidade com base na qual enfrentaremos por meios pacíficos a transformação dos conflitos que a interdependência possa gerar.

\section{Uma proposta epistemológica com base na nossa filosofia para fazer as pazes}

No contexto desta concepção dos seres humanos para fazer as pazes, uma das perguntas que fazemos é a de como sabemos que podemos fazer as pazes. De uma forma mais académica, qual é o estatuto epistemológico da investigação para a paz? São científicos, os estudos para a paz?

Estas são interrogações que preocuparam os "clássicos" da investigação para a paz, as relações internacionais, os estudos sobre conflitos, a ajuda humanitária e a cooperação para o desenvolvimento. Por exemplo, Galtung (2003) considera que os estudos sobre a paz são a exploração científica das condições pacíficas para reduzir a violência que têm os seres humanos em sociedade como o seu objecto central. Neste sentido, os estudos sobre a paz constituem uma ciência social aplicada, clara e explicitamente orientada por valores. Boulding (1994) crê nas possibilidades da ciência para organizarmos um futuro melhor a partir da teoria dos sistemas. Neste sentido, propõe que se dê uma "evolução noogenética", uma progressão nos sistemas de conhecimento (nóos) com os quais os seres humanos se organizam e que nos levaria à organização das relações humanas baseadas na ameaça a outras baseadas no intercâmbio e na integração (Boulding, 1992). Rapoport (1992) parte, assim, de uma combinação da teoria da evolução e da de sistemas no contexto da evolução da "noosfera" ou esfera do conhecimento. Na organização sistémica das nossas relações, criámos o sistema de guerra, mas tivemos latente a possibilidade de criar o sistema de paz. Dependendo das políticas que realizarmos, poderemos afirmar que chegou a hora da ideia da paz, como reza o título do seu livro de Rapoport que estamos a citar (Peace, an Idea Whose Time Has Come). Também a teoria das relações internacionais tem vindo a apresentar alternativas ao chamado realismo inicial, que propunha uma espécie de anarquia na ordem mundial concebida unicamente a partir da perspectiva dos estados nacionais (Bull, 1995). Estas alternativas têm origem na teoria crítica (Rengger e Hoffman, 1992) e, inclusivamente, em algumas teorias feministas (Ship, 1994). Finalmente, os estudos sobre desenvolvimento estão a passar das posições iniciais, que, em nome do desenvolvimento, continuavam a colonizar, para propostas mais atentas às próprias economias de subsistência dos povos empobrecidos (Sachs, 1996). 
É evidente o interesse filosófico do estatuto epistemológico da investigação e dos estudos para a paz. Inicialmente, pela reacção académica de "encontrar um sítio" na universidade para este tipo de estudos. Neste sentido, o esforço primeiro era "demonstrar", de alguma maneira, que também estas investigações e estes estudos eram científicos e tinham lugar na vida universitária. No entanto, na medida em que fomos indo mais fundo e continuamos a fazê-lo (Martínez Guzmán, 2001: 2005), o problema já não é se eles são ou não científicos. A questão que se coloca é se, em nome da "ciência" tal como se desenvolveu desde a modernidade-ocidental, iluminista e da parte rica do mundo - continuámos a dominar, excluindo e marginalizando outros saberes, culturas e formas de entender a ciência. Recordemos que o que consideramos como problema filosófico fundamental da investigação e dos estudos para a paz não é o nível de reconhecimento académico que possamos alcançar, mas sim a possibilidade de transformar por meios pacíficos o sofrimento que os seres humanos geram uns aos outros e à própria natureza. Evidentemente, no nosso caso, como académicos, temos a responsabilidade de usar com rigor todos os instrumentos que a universidade coloca à nossa disposição, como esta mesma revista, para fazer frente a esse problema. De outra forma, estaríamos a fazer mera estética academicista.

Daqui que as nossas reflexões filosóficas sobre a cientificidade da investigação e dos estudos para a paz nos tenham conduzido a questionar a própria noção de ciência herdada do nosso contexto ocidental e a propor o que costumamos chamar "eixos da mudança epistemológica" (Martínez Guzmán, 2001: 114). No entanto, há que afirmar que o fazemos, como sucedeu na primeira parte, utilizando os mesmos instrumentos filosóficos em que nos formámos, submetendo-os à interpelação de outros instrumentos e outras formas de entender os saberes mais ligados ao sofrimento dos que foram marginalizados e excluídos dos saberes dominantes: as mulheres e outros colectivos, povos e culturas.

O reconhecimento autocrítico do próprio ponto de partida, "horizonte hermenêutico" ou interpretativo a partir do qual fazemos as nossas reflexões "científicas", já faz parte dos eixos da mudança epistemológica que propomos. Alguns dos preconceitos herdados da ciência moderna ocidental dizem-nos que temos que ser objectivos, neutros e que a nossa reflexão, a ser científica, não deve estar comprometida com nenhum tipo de valores. No entanto, estas afirmações estavam já comprometidas com uma valoração do que era científico e o que não era, e, o que é pior, já excluíam outras formas de entender os saberes e as pessoas e colectivos que usavam esses saberes. 
Pois bem, a nossa proposta é que não é possível tal objectividade, neutralidade, nem falta de compromisso com valores. A nossa alternativa à objectividade baseia-se na teoria da performatividade já mencionada (Martínez Guzmán, 2001: 219). Para ser científico, já não se trata de afirmar que existe uma relação directa sujeito-objecto, e que a objectividade consiste principalmente na quantificação dos fenómenos que nos mostram a realidade tal como é. As afirmações científicas sobre a realidade - no nosso caso, sobre as diversas maneiras de fazer as pazes - fazem parte da configuração ou performação das relações humanas de que sempre podemos pedir-nos contas. Baseiam-se na "intersubjectividade" e interpelação mútua. A intersubjectividade é a alternativa à objectividade.

Esta intersubjectividade e interpelação mútua não rejeitam o compromisso com valores, no nosso caso, com as diversas formas de entender a paz e a rede conceptual associada, justiça, instituições de governação e relações pessoais de ternura e carinho, que incluem a perspectiva da diferença sexual e a dos "povos do Sul". Do que se trata, precisamente, é de tornar explícito o que valorizamos, e submetê-lo ao debate público e à interpelação, sobretudo de quem possa ficar à margem e sofrer a dominação dos nossos próprios valores e crenças.

Como denunciaram as feministas, ficámos "cegos" aos nossos próprios preconceitos patriarcais e a cegueira estendeu-se a outras formas de dominação, e ficámos obnubilados pela cientificidade objectiva e neutral. Por oposição, a conclusão a que chegamos é que as gentes, os povos, as culturas têm direito aos seus próprios saberes, e têm direitos epistemológicos.

Para além disso, a intersubjectividade e a interpelação mútua como formas de conhecimento são coerentes com a nossa concepção de que os seres humanos têm capacidades ou competências para fazer as pazes. Acrescentaríamos agora que "o sabemos". Sabemos que temos estas competências e podemos pedir-nos contas, performativamente, por que tipo de competências exercemos nas nossas relações. É certo que há uma relação entre saber e poder. Esta relação pode ser usada "para o mal", impondo um tipo de saber e submetendo e excluindo outros saberes. No entanto, também podemos usar a relação entre saber e poder "para o bem". Quando dizemos que alguém sabe algo, aludimos a certas capacidades para identificar aquilo que estamos a mencionar, se se tiver oportunidade, ou que se tem a oportunidade de identificar se tiver a capacidade, ou até ambas as coisas (Austin, 1975: 90 ss., 214). Saber e poder são verbos que aparecem como nós de redes que os unem a outros conceitos, noções e expressões, como ter oportunidades, capacidades, ter tido determinadas experiências, ter sido educado de determinadas formas, ter exercido e desenvolvido um determinado tipo 
e quantidade de argúcia, ter aprendido a discriminar ou a discernir, ter adquirido determinados usos linguísticos, ser capaz de corrigir esses mesmos usos linguísticos, estar numa determinada posição que me permite saber determinadas coisas. etc. Estou a estudar como esse reconhecimento das capacidades de saber, das que se pode fazer uso se nos dermos a uns e umas e a outros e outras as oportunidades adequadas, está relacionado com a noção de desenvolvimento em liberdade proposta por Amartya Sen (2000): desenvolvimento entendido como o exercício livre das próprias capacidades de acordo com o que cada pessoa e cultura considera digno de valorizar.

Explicar desta forma o que significa saber, é também coerente com a nossa teoria da performatividade: saber é algo que fazemos, realizamos, executamos ou "performamos" enquanto seres humanos. Daí que se tornem confusas algumas terminologias supostamente científicas como "recolher dados", como se o conhecimento fosse algo que nos é dado passivamente e não algo que fazemos. Saber é outra forma de poder fazer e, quando dizemos que sabemos, estamos sujeitos a ser interpelados sobre se o sabemos "verdadeiramente" ou "apenas cremos nisso" ou pensamos que "é provável". Há um paralelismo entre dizer "eu sei" e "eu prometo" que é o exemplo mais clássico de performatividade, porque, quando prometemos, o importante não é a que nos referimos, mas sim o que nos comprometemos a cumprir, ficando sujeitos a que nos peçam contas sobre se cumprimos ou não. Ao dizer que sei, como ao dizer que prometo, fico comprometido com os demais que "confiam" que o sei e não simplesmente que o creio ou considero provável.

Do mesmo modo, esta concepção do saber sobre as nossas competências para fazer as pazes considera também o saber ou o conhecimento, como estamos a ver, como uma competência ou capacidade mais dos seres humanos. Neste sentido, perguntar pelo estatuto "epistemológico" da investigação e dos estudos para a paz, a partir da minha proposta filosófica, já não significa apenas perguntar pelo estatuto da cientificidade destes estudos e investigação em comparação com o modelo ocidental moderno. É, antes, perguntar pelas capacidades ou competências que temos enquanto seres humanos para dizer que sabemos que temos competências ou capacidades para fazer as pazes. Efectivamente, em grego episteme significa ciência, conhecimento, mas também inteligência, saber, destreza, arte, habilidade. Epístamai significa "ser prático" e "ser capaz", entendido, hábil e, efectivamente, também significa pensar, crer e conhecer. O adjectivo epistámenos aplica-se a quem é hábil, prático, conhecedor, entendido, o que faz as coisas com arte, com destreza. Por conseguinte, baseados na nossa perspectiva filosófica, os estudos e a investigação para a paz indagam teorica- 
mente e na prática das relações humanas as competências, capacidades, habilitações e conhecimentos relativos à transformação pacífica dos conflitos, às relações internacionais, à ajuda humanitária e aos estudos do pós-desenvolvimento.

De facto, procurando (Martínez Guzmán, 2004c) a origem grega da expressão "trabalhadores pela paz" que herdámos do Sermão da Montanha no evangelho de Mateus $(5,9)$, a palavra grega utilizada pelo evangelista é eirenopoioi. Eireno quer dizer paz, e na mitologia grega era irmã da justiça e do bom governo ou da boa lei. Por conseguinte, quem trabalha pela paz trabalha também pela justiça e pelo bom governo. A segunda parte da palavra está relacionada com a poíesis. É uma palavra utilizada por Aristóteles para se referir a um tipo de ciências ou epistamai que estão entre as teóricas e as prácticas ou morais. Portanto, quem trabalha pela paz dedica-se a um tipo de actividade produtiva que estabelece uma ponte entre a teoria que estuda aquilo que não pode ser de outra maneira (por exemplo que dois mais dois sejam quatro, não pode ser de outra maneira), e as acções morais que podemos fazer de muitas maneiras diferentes, por isso podem ser boas ou más consoante o que façamos uns e umas a outros e outras. Para além disso, estas ciências poiéticas ou produtivas, de onde vem, por exemplo, "poesia", fazem-se com a liberdade criativa que temos enquanto seres humanos para fazermos as coisas de muitas maneiras diferentes. Para isso, podemos usar a inteligência, a técnica e a potência ou capacidades de quem realiza a acção.

Deste modo, quem trabalha pela paz realiza um tipo de actividade entre a teoria e a prática, com inteligência, técnica e capacidade, usando a sua liberdade e sempre sujeito e sujeita a que se lhe peça contas pelo que faz. Por exemplo, nos conflitos interpessoais podemos excluir-nos e marginalizar-nos, ou podemos transformá-los por meios pacíficos, procurando a justiça, o acordo e a expressão do carinho e da ternura. Nos conflitos bélicos, podemos bombardear o Iraque ou podemos utilizar os meios pacíficos de frear a proliferação de armamento, transformar as Nações Unidas, promover o Tribunal Penal Internacional e criar instituições globais e locais que afrontem o problema da pobreza e da miséria humana, como veremos em seguida.

Finalmente, a epistemologia dos estudos e da investigação para a paz muda também o centro de investigação da paz negativa para a paz positiva. Parecia que aprendíamos sobre a paz a partir do que não é a paz, a partir da análise da violência e das guerras. No entanto, na nossa proposta de filosofia para fazer as pazes como reconstrução normativa das competências humanas para viver em paz, chegamos a propor que o que é básico ou 
originário nas relações humanas é precisamente a paz: as diversas formas em que os seres humanos se relacionam de forma pacífica na configuração ou performance intersubjectiva das nossas relações.

Não é, portanto, a paz que se entende como a alternativa à violência - os diferentes tipos de violência é que supõem a ruptura da diversidade de formas de viver em paz com as quais configuramos originariamente as nossas relações enquanto seres humanos. A sensação de que a violência é que é o elemento primário vem de estar-se a pensar numa paz em termos absolutos, perfeita. Na realidade, esta paz absoluta e perfeita converte-se numa forma totalitária de dominação porque exclui a diversidade de saberes de acordo com os quais os seres humanos podem organizar as suas formas de vida de maneira pacífica. Por este motivo, alguns autores (Muñoz, 2001), para romper com a "esquizofrenia cognitiva" de investigar a paz a partir da violência, propõem a noção de "paz imperfeita": a paz, ou melhor, as pazes em processo sempre inacabado de constituição das relações humanas por meios pacíficos.

\section{Políticas para um localismo cosmopolita}

A concepção de seres humanos que propusemos e a mudança epistemológica na qual temos vindo a trabalhar têm implicações políticas. Políticas para a fragilidade a partir da qual exercemos as nossas competências para fazer as pazes, e políticas para o reconhecimento de que os povos têm direito aos seus próprios saberes.

Pois bem, estamos a trabalhar no sentido da aplicação global e local dessas políticas, como fomos apontando nos exemplos que mencionámos, a uma possível "Nova Ordem Mundial". De certa forma, a nossa aproximação continua a ser uma actualização do legado kantiano com as matizes críticas que a perspectiva da diferença sexual e os saberes do Sul puderam introduzir.

Assim, actualizamos a proposta kantiana (Martínez Guzmán, 1997) de um direito cosmopolita ou direito público da humanidade baseado na afirmação de que a violação do direito numa parte do mundo afecta toda a humanidade. Também com a proposta de que o direito cosmopolita se expressa como direito da "hospitalidade": ninguém tem mais direito do que o outro a estar numa parte do mundo, porque temos em comum a propriedade do solo que nos encerra no globo que é a Terra. Este é o sentido genuíno de globalização: a necessidade de partilhar "os lugares" da Terra, e não a imposição unilateral a todos os espaços do mundo de uma forma de entender a economia, anulando as possibilidades locais de sobrevivência.

A partir dessas reflexões transkantianas estamos a estudar as possibilidades de uma democracia cosmopolita (Archibugi e Held, 1995; Held, 1997; 
Held e McGrew, 2003), que vão mais além da ordem mundial de Vestefália de 1648, que considerava como únicos actores da ordem internacional os Estados nacionais. Assim, a democracia cosmopolita estabeleceria relações entre os novos actores da ordem mundial: os Estados entre eles mesmos, os Estados e os cidadãos e cidadãs de outros Estados, agrupamentos regionais de Estados, relações entre os próprios cidadãos e cidadãs no contexto de uma Sociedade Civil Global, transformação de órgãos como a ONU, potencialização do Tribunal Penal Internacional, instituições globais de controlo da economia que façam frente ao tema da pobreza e da fome, instituições globais de diálogo de crenças e civilizações...

Tudo isso a partir do alerta crítico, avançado por Kant, de que haverá algum Estado que terá a tentação de se converter num governo mundial. Perante essa ordem mundial unipolar, como a que agora estamos a viver por parte do governo dos EUA, Kant, na linguagem da sua época, advertia já que a natureza parece querer outra coisa e vale-se de dois meios para isso: a diversidade de línguas e a diversidade de crenças. Certamente, insistia Kant, esta diversidade pode ser motivo de guerras e disputas. No entanto, dependendo das culturas que promovamos, na nossa interpretação, poderemos potenciar as nossas capacidades para a violência a partir da arrogância, ou promover culturas para fazer as pazes, a partir da assunção da nossa fragilidade e vulnerabilidade como demonstração da nossa interdependência.

Utilizámos também (Martínez Guzmán, 2001: 240 ss.) a terminologia de Richard Falk "constitucionalismo global” (Falk et al., 1993). No entanto, uma vez que não concordamos com algumas das suas posições sobre o modo de abordar os calamitosos ataques terroristas do 11 de Setembro de 2001 (Falk, 2002), ao manter essa terminologia optaríamos por usar meios pacíficos tal como propõe Ferrajoli (2004). Creio que Ferrajoli poderia contribuir com a necessária garantia jurídica para as propostas de democracia cosmopolita a que me tenho referido. Necessitamos de uma actualização da proposta kantiana de que a violação do direito numa parte do mundo afecta toda a humanidade, com a criação de uma esfera pública global, com a criação de instituições de governo e instituições de garantia, especialmente a favor dos mais frágeis. Estas instituições de governação global obrigar-nos-ão a fazer frente ao problema do terrorismo global a partir das suas causas mais profundas que continuam a ser as desigualdades globais, a marginalização e a exclusão (Martínez Guzmán, 2004b).

De qualquer forma, na medida em que desde o princípio mostrámos a nossa preocupação autocrítica perante generalizações precipitadas que deixaram à margem mulheres, outros homens e povos inteiros, o nosso 
cosmopolitismo terá que ter mais os pés na terra. Daí que retomemos dos estudos críticos do desenvolvimento a expressão "localismo cosmopolita" (Sachs, 1996). Na nossa interpretação (Martínez Guzmán, 2001:312,327ss.), seria uma tentativa de conjugar o nosso compromisso mais imediato com a colectividade a que pertencemos, e a solidariedade com os seres humanos onde os haja. Para isso, deveríamos assumir o nosso próprio lugar, e abrirmo-nos ao reconhecimento de "outros lugares", nos quais vivem seres humanos e comunidades com as suas próprias formas vernáculas de expressão, e das maneiras como esses seres e comunidades entendem o cultivo das relações humanas e da natureza. Assim, deveríamos ser educados para a assunção de uma identidade "híbrida" mais do que "pura", que mostre a complexidade de culturas, seres humanos e histórias que se cruzaram pelo lugar no qual a minha identidade tem as suas raízes.

O sentido dinâmico de identidade que proponho, o significado de ser "nós próprios", é como um punhado ou uma braçada de peculiaridades que nos caracterizam. Digo "punhado" porque é uma diversidade unida pela mão, e "braçada" porque tem o sentido de conjunto de coisas atadas. Interpreto portanto que, como braçada ou punhado de peculiaridades, as identidades pessoais ou colectivas mostram uma espécie de "unidade na diversidade de uns e umas com outros e outras": eu próprio sou pai, esposo, filho, ser humano, homem, branco, do Norte do mundo, de cultura cristã, valenciano, espanhol, europeu, professor numa universidade valenciana e neste momento estou a tentar colaborar com uma revista de Portugal. Depende das características que enfatize na relação com os outros e com as outras. Possivelmente, sem "as outras e os outros" não teria identidade, não poderia ser "eu mesmo". O perigo está quando pensamos que só podemos reafirmar a nossa identidade "contra" e não "com" os outros. Então as nossas identidades convertem-se em "assassinas" (Maalouf, 1999).

O localismo cosmopolita reivindica a diversidade de lugares perante a universalidade uniforme da concepção do mundo como espaço. O espaço é uma abstracção que homogeneiza, enquanto os lugares permitem o cruzar das diversas maneiras de acordo com as quais concebemos as relações humanas e o reconhecimento de uma multiplicidade de identidades, com as suas histórias, as suas línguas, as suas culturas, as suas concepções do mundo, as suas crenças, formas locais de fazer política, de governação, administração da justiça, transformação de conflitos e partilha de recursos. Reivindicar para todos os seres humanos o seu "lugar", mesmo no sentido de "lugarejo", ser de uma aldeia, com todos os punhados e braçadas de peculiaridades que nos possam caracterizar, é, de certa forma, reconhecer e deixar que concedam poder a si mesmos os que excluíamos porque "não eram dos 
nossos", não crêem no nosso Deus", "eram subdesenvolvidos", ou eram simplesmente mulheres. Significa assumir e reconhecer as peculiaridades, capacidades e poderes do nosso "país" e reconhecer os outros países, os outros lugares, como uma afirmação mútua das respectivas identidades. Também supõe recuperar aquilo a que na Ética Comunicativa chamamos "mundo da vida quotidiana" perante os sistemas de colonização da nossa vida comum que nós próprios, seres humanos, criámos: o dinheiro e o poder (Habermas, 1987: II, 432)

É em tudo isto que estamos a trabalhar.

Tradução de

Tatiana Moura

\section{Referências Bibliográficas}

Apel, Karl-Otto (1986), "Die Logos-Auszeichnung der menschlichen Sprache. Die philosophische Tragweite der Sprechakttheorie”, in Hans-Georg Bosshardt (org.), Perspektiven aufSprache. Interdisziplinäre Beitrage zum Gedenken an Hans Hörmann. Berlin/New York: de Gruyter, 45-87.

Archibugi, Daniele; Held, David (1995), Cosmopolitan Democracy: An Agenda for a New World Order. Cambridge, MA: Polity Press.

Arendt, Hannah (1996), La condición bumana. Barcelona: Ediciones Paidós.

Arendt, Hannah (1998), "Sobre la violencia", in Hannah Arendt (org.), Crisis de la república. Madrid: Taurus.

Arias, Gonzalo (1995), El proyecto político de la noviolencia. Madrid: Editorial Nueva Utopía.

Austin, J.L. (1971), Palabras y Acciones. Cómo hacer cosas con palabras. Buenos Aires: Paidós.

Austin, J.L. (1975), Ensayos Filosóficos. Madrid: Revista de Occidente.

Barber, Benjamín R. (2004), El imperio del miedo. Guerra, terrorismo y democracia. Barcelona: Paidós.

Boulding, Elise; Boulding, Kenneth E. (1994), The Future. Images and Processes. London: Sage.

Boulding, Kenneth E. (1992), Las tres caras del poder. Barcelona-Buenos Aires-México: Ediciones Paidós.

Bull, Hedley (1995), The Anarchical Society: A Study of Order in World Politics. New York: Columbia University Press.

Falk, Richard (2002), "Identifying Limits on a Borderless Map”, Ethics E International Affairs, 16(1), http://www.carnegiecouncil.org/viewMedia.php?prmTemplateID= 8\&prmID=97\#falk1 [Consulta 5/11/2004]. 
Falk, Richard A. et al. (1993), The Constitutional Foundations of World Peace. Albany: State University of New York Press.

Ferrajoli, Luigi (2004), Razones jurídicas del pacificismo. Madrid: Trotta.

Galtung, Johan (2003), Pazpor medios pacíficos. Paz y conflicto, desarrollo y civilización. Gernika: Bakeaz-Gernika Gogoratuz.

Habermas, Jürgen (1984), "El concepto de poder de Hanna Arendt”, in Jürgen Habermas (org.), Perfiles filosófico-políticos. Madrid: Taurus.

Habermas, Jürgen (1987), Teoría de la acción comunicativa. Madrid: Taurus.

Habermas, Jürgen (1998), Facticidad y validez. Sobre el derecho y el Estado democrático de derecho en términos de teoría del discurso. Madrid: Trotta.

Held, David (1997), La democracia y el orden global: del Estado moderno al gobierno cosmopolita. Barcelona: Paidós.

Held, David; McGrew, Anthony G. (2003), Globalización/anti-globalización. Sobre la reconstrucción del orden mundial. Barcelona: Paidós.

Landmann, Michael (1961), Antropología filosófica. Autointerpretación del bombre en la bistoria y en el presente. México: UTEHA.

Maalouf, Amin (1999), Identidades asesinas. Madrid: Alianza.

Martínez Guzmán, Vicent (org.) (1997), Kant: La pazperpetua, doscientos años después. València: Nau Llibres.

Martínez Guzmán, Vicent (1999), "El silencio como interpelación: Paz y Conflicto”, in Farrell, Mary e Dora Sales (orgs.) (1999), El silencio en la comunicación bumana. Castelló: Seminari d'Investigació Feminista. Universitat Jaume I, 107-120.

Martínez Guzmán, Vicent (2001), Filosofía para hacer las paces. Barcelona: Icaria.

Martínez Guzmán, Vicent (2003), "Políticas para la diversidad: Hospitalidad contra Extranjería”, Convergencia. Revista de Ciencias Sociales, 10(33), 19-44.

Martínez Guzmán, Vicent (2004a), "La investigación para la paz después del 11 de septiembre. Una perspectiva desde la filosofía para la paz”, Papeles de Cuestiones Internacionales, 85, 33-42.

Martínez Guzmán, Vicent (2004b), "Teorías de la guerra en el contexto político de comienzos del siglo XXI”, in Ildefonso Murillo (org.), Filosofía práctica y persona bumana. Salamanca: Publicaciones Universidad Pontificia de Salamanca / Ediciones Diálogo Filosófico, 479-491.

Martínez Guzmán, Vicent (2004c), "Vint reptes en el treball amb jóvens: animació i educació per a la pau”, Revista Animació. Institut Valencià de la Joventut, 17, 3-5, http://www.ivaj.es/infoivaj/curso/eaj/sumario_revista.htm.

Martínez Guzmán, Vicent (2005), Podemos hacer las paces. Reflexiones éticas tras el 11-S y el 11-M. Bilbao: Desclée de Brouwer.

Muñoz, Francisco A. (2001), La paz imperfecta. Granada: Universidad de Granada.

Rapoport, Anatol (1992), Peace. An Idea Whose Time Has Come. Ann Arbor: The University of Michigan Press. 
Reardon, Betty (1985), Sexism and the War System. New York/London: Teachers College, Columbia University.

Rengger, Nick; Hoffman, Mark (1992), "Modernity, Postmodernism and International Relations”, in Joe Doherty et al. (orgs.), Postmodernism and the Social Sciences. London: Macmillan, 127-147.

Roberts, Edward A.; Pastor, Bárbara (1997), Diccionario etimológico indoeuropeo de la lengua española. Madrid: Alianza.

Sachs, Wolfgang (org.) (1996), Diccionario del Desarrollo. Una guía del conocimiento como poder. Lima: PRATEC.

Sen, Amartya Kumar (2000), Desarrollo y libertad. Barcelona: Editorial Planeta.

Ship, Susan Judith (1994), "And What About Gender? Feminism in International Relations Theory's Third Debate”, in Claire Turenne Sjolander; Wayne S. Cox (orgs.), Beyond Positivism: Critical Reflections on International Relations. London/Boulder: Lynne Rienner Publishers, 11-36.

Villa Martínez, Marta Inés (org.) (2002), El Miedo. Reflexiones sobre su dimensión social y cultural. Medellín: Corporación Región. 